\title{
Economic and Technological Aspects of the European Competitiveness: A Multicriteria Approach
}

\author{
K. Kosmidou, M. Doumpos and C. Zopounidis \\ Technical University of Crete, University Campus \\ F. Voulgaris \\ Technological Educational Institute of Crete, Heraklion
}

\begin{abstract}
Competitiveness constitutes a primary goal of each country for the accomplishment of its economic and technological targets. The evaluation of competitiveness is considered as a major problem that has risen during the last years due to the globalization and the rapid changes in the socio-economic and technological environment. Therefore, it is interesting to investigate the economic and technological aspects of the competitiveness of the European countries. The present study uses a sample of 14 countries-members of the European Union, as well as United States and Japan for comparison reasons. Taking into consideration several technological and economic indicators and using data from a recent study of the European Committee, this paper presents the evaluation of the competitiveness of the countries using a multicriteria ranking methodology (the PROMETHEE II method). The results of this paper contribute to the determination of the most and least competitive as well as technologically developed countries.
\end{abstract}

- JEL Classification: C65, 031, N24

- Keywords: competitiveness, technological innovation, multicriteria decision aid

\footnotetext{
*Corresponding address: Prof. C. Zopounidis, Technical University of Crete, Dept. of Production Engineering and Management, Financial Engineering Laboratory, University Campus, 73100 Chania, Greece Tel: +30-28210-37236 Fax: +30-28210-69410 E-mail: kostas@dpem.tuc.gr, zopounid@cha.forthnet.gr (c)2004-Center for International Economics, Sejong Institution, All Rights Reserved.
} 


\section{Introduction}

The European Union has gradually adopted the policy of developing measures and initiatives to tackle negative effects arising from trade liberalization, both at national and international levels, so as to make sure that trade, natural resources, human capabilities, research and educational institutions, government organizations, financial systems and cultural and social values are mutually supportive for the sake of sustainable development.

Due to the above, over the past decades, many leading economies made significant progress in advancing their drivers of competitiveness. Macroeconomic balances improved, markets were opened, government regulation became more streamlined and infrastructure was upgraded.

It becomes obvious that the competitive environment a country provides influences its economic performance and technological development. Therefore, the evaluation of competitiveness is considered as a major problem that has risen during the last years due to the globalization and the rapid changes in the socioeconomic and technological environment. Thus, it is of prime importance to investigate the economic and technological aspects of a country competitiveness.

The paper focuses on the European case and examines mainly the technological competitiveness of the European countries based only on one study, coming from the European Committee. On the one hand, this is very limitative for our research, but on the other hand it gives a new theoretical background for further research on this subject. This constitutes the originality of our paper, which is organized as follows: Section 2 presents brief literature review of studies conducted on the analysis of countries' competitiveness. Section 3 underlines the methodology employed and the sample data used in this study. Section 4 describes the obtained empirical results. Finally, in section 5 the concluding remarks are discussed.

\section{Literature review}

The analysis of countries' competitiveness has been a significant research topic since the early 1980s. International organizations, governments and policy makers are interested in analyzing the competitiveness of countries in order to ensure sustainable development. This has motivated leading international organizations in analyzing competitiveness and publishing appropriate reports. The most wellknown of these reports is the World Competitiveness Report (WCR) published 
annually since 1982, by the Institute for Management Development (IMD) and the World Economic Forum (WEF). The purpose of the WCR is to provide a ranking of a selected group of countries with respect to a set of more than 350 political, social and economic indicators. The methodology employed for obtaining the rankings presented in the WCR is however available to the public, possibly due to proprietary reasons. The WCR studies the competitiveness of two groups of countries. In the first group, the OECD countries are included; namely, Australia, Austria, Belgium, Canada, Denmark, France, Finland, Germany, Greece, Ireland, Italy, Japan, the Netherlands, New Zealand, Norway, Portugal, Spain, Sweden, Switzerland, Turkey, United Kingdom and the United States. The second group consists of newly industrialized countries: Brazil, Chili, Hong Kong, Hungary, India, Indonesia, Malaysia, Mexico, Pakistan, Singapore, South Korea, Taiwan, Thailand and Venezuela. The competitiveness rating and ranking are separately done for these two groups of countries. Consequently, the competitiveness of a country in a group cannot be compared with that of a country in the other group. The WCR defines the overall competitiveness of a country as a function of 8 major factors, such as domestic economic strength, internationalization, government, finance, infrastructure, management, science and technology and people. The methodology of the WCR can be summarized in five steps: 1) standardization of the indicators, 2) aggregation of the indicators into composite indicators, 3) aggregation of the composite indicators into sub-factors, 4) aggregation of the subfactors into factors, and 5) aggregation of the factors into overall competitiveness. However, it should be noted that the WCR does not suggest any particular prescriptions or agendas for the countries to pursue, but offers some general ideas as to the competitiveness of nations.

On the other hand, the study of Porter (1990) proposes a methodology to analyze the competitiveness of countries and furthermore he develops an agenda for each of country to pursue in order to become internationally more competitive. The basic idea of his methodology is to analyze the economy of a country, sector by sector, in terms of factor conditions, demand conditions, supporting and related industries, firm strategy, structure and rivalry, government role and chance factor. The proposed methodology is applied on a sample of 10 countries and the obtained results are then transformed into a set of recommendations to form an agenda for each country to adopt.

Oral and Chabchoub (1996) studied the rankings provided in the WCR in order to develop a specific functional additive model that could reproduce these rankings. 
The development of the model was based on mathematical programming techniques. The same authors in 1997 used a similar approach to the methodology of the WCR through exact replications of its rankings at all levels of aggregation by using an estimation model based on mathematical programming, called WEM (Weight Estimation Model). The basic idea behind WEM was to increase the chances of replicating the WCR rankings at all levels by assuming different weights to a given indicator for different countries, rather than imposing the same weight for all countries. Although different weights for an indicator are allowed, WEM would seek to minimize the differences between the countries regarding the importance of an indicator.

Except for the WCR report, recently the European Commission also published a report (European Commission, 2001). The preparation of this report was motivated by the Lisbon Summit of the European Council in March 2000, where the European Union set itself a strategic goal for the next decade: to become the most competitive and dynamic knowledge-based economy in the world. In order to implement the Lisbon strategy in the field of $R \& D$, the Council, in its Resolution of June 2000, called upon the European Commission to set up a methodology and indicators for the benchmarking of national research policies in Europe in the framework of the creation of a European Research Area. The publication of the European Commissions report is the first phase of the exercise of benchmarking of national research policies through the presentation of a set of appropriate indicators which cover four groups, such as a) human resources in $R \& D$, including the attractiveness of strategy and technology professions, b) public and private investment in $R \& D$, c) scientific and technological productivity, d) the impact of $\mathrm{R} \& \mathrm{D}$ on economic competitiveness and employment. The aim of this set of indicators was to provide a broad comparative overview of the performance of member states in relation to the above themes, using currently available and internationally statistics. Wherever possible, comparative indicators have been provided for the USA and Japan.

Taking into consideration the technological and economic indicators of the above report, this paper evaluates the competitiveness of the European member countries using a multicriteria ranking methodology. 


\section{Methodology}

\section{A. Data}

The analysis presented in this study involves 14 countries-members of the European Union, as well as United States and Japan for comparison reasons. Appropriate data were gathered for the European Commission's report (European Commission, 2001). The data involve 37 indicators measuring the competitiveness and the technological performance of the member states and the countries of USA and Japan. The researchers of the European Committee ranked each member state in each criterion from the best to the worst value (for example, for the indicator: total researchers per 1000 workforces: Finland $\left(1^{\text {st }}\right)$ with performance $10.62, \ldots$, Greece $\left(15^{\text {th }}\right)$ with performance 2.57). Moreover, for each indicator its average annual growth was also calculated over a time period. However, it should be noted that the time period used to estimate average annual growth of each indicator was not the same for all countries (possibly due to data availability reasons). This poses a barrier in the analysis.

Nevertheless, the main shortcoming of the European Commission's report is that it only provides useful competitiveness information and partial rankings on each indicators used, without concluding to an overall evaluation of the countries with regard to their competitiveness and technological performance. Such an overall evaluation is necessary in order to be able to develop appropriate policy measures and recommendations.

To address this issue, the present study uses data from the European Commission's report on 14 countries members of the European Union (except Luxembourg for which there were too many missing data), as well as for USA and Japan. The time period of the analysis involves the year 1999 (this is the year to which the data reported in the European Commission's report refer to). From the 37 indicators considered in the European Commission's report a more compact set of 10 indicators is used in the analysis. These indicators are selected on the basis of the available data (for many indicators the report does not provide complete data for all countries) as well as their ability to represent all four groups of indicators considered in the European Commission's report (human resources in R\&D, public and private investment in $\mathrm{R} \& \mathrm{D}$, scientific and technological productivity, impact of $\mathrm{R} \& \mathrm{D}$ on economic competitiveness and employment). The selected indicators are presented in Table 1 (indicators' definitions), while Table 2 presents the data used 
for the evaluation of the competitiveness of the countries in the sample.

\section{B. Method}

The evaluation of the competitiveness of member states among the economic and technological aspects has been carried out using the PROMETHEE II multicriteria method (Preference Ranking Organization Method of Enrichment Evaluations; Brans \& Vincke, 1985), which is suitable for performance evaluation problems where multiple evaluation criteria are involved. The PROMETHEE II

Table 1. Evaluation criteria of technological competitiveness

\begin{tabular}{ll}
\hline$g_{1}$ & Total researchers per 1000 workforce \\
$g_{2}$ & Total new science and technology PhDs per 1000 population \\
$g_{3}$ & Total research and development expenditure/GDP \\
$g_{4}$ & Venture capital investments/GDP \\
$g_{5}$ & European patents per million population \\
$g_{6}$ & US patents per million population \\
$g_{7}$ & Number of scientific publications per million of population \\
$g_{8}$ & Percentage of innovative firms cooperating with other firms \\
$g_{9}$ & Labor productivity (GDP per hour worked) \\
$g_{10}$ & World market share of exports of high-tech products \\
\hline
\end{tabular}

Table $2^{\bullet}$ Performance of the examined countries to the selected indicators of technological competitiveness

\begin{tabular}{lrlrrrrrrrr}
\hline & $g_{1}$ & \multicolumn{1}{l}{$g_{2}$} & \multicolumn{1}{c}{$g_{3}$} & \multicolumn{1}{c}{$g_{4}$} & \multicolumn{1}{c}{$g_{5}$} & \multicolumn{1}{c}{$g_{6}$} & \multicolumn{1}{c}{$g_{7}$} & \multicolumn{1}{c}{$g_{8}$} & \multicolumn{1}{c}{$g_{9}$} & \multicolumn{1}{c}{$g_{10}$} \\
\hline Belgium & 6.11 & 0.36 & 1.98 & 0.9 & 126 & 88 & 810 & 29 & 39.2 & 1.44 \\
The Netherlands & 5.05 & 0.35 & 1.94 & 0.91 & 191 & 93 & 963 & 29 & 37.3 & 4.54 \\
Austria & 4.86 & 0.56 & 1.78 & 0.07 & 134 & 77 & 717 & 23 & 32.7 & 0.74 \\
Germany & 6.07 & 0.75 & 2.46 & 0.5 & 258 & 133 & 657 & 23 & 32.4 & 7.32 \\
G. Britain & 5.54 & 0.63 & 1.87 & 0.19 & 109 & 72 & 949 & 31 & 29.1 & 6.31 \\
USA & 8.08 & 0.47 & 2.62 & 1.16 & 144 & 315 & 708 & 0 & 33.9 & 19.75 \\
Portugal & 3.27 & 0.23 & 0.78 & 0.08 & 3 & 1 & 248 & 18 & 19.6 & 0.1 \\
Japan & 9.26 & 0.24 & 2.91 & 0.99 & 134 & 249 & 498 & 0 & 25.5 & 9.95 \\
France & 6.14 & 0.71 & 2.17 & 0.39 & 120 & 69 & 652 & 30 & 34.9 & 7.39 \\
Italy & 3.33 & 0.17 & 1.04 & 0.13 & 62 & 32 & 457 & 10 & 35.4 & 1.64 \\
Finland & 10.62 & 0.97 & 3.3 & 0.56 & 298 & 129 & 1.157 & 70 & 30.1 & 0.83 \\
Spain & 3.77 & 0.43 & 0.9 & 0.16 & 20 & 8 & 471 & 19 & 25.1 & 0.59 \\
Denmark & 6.46 & 0.56 & 2.07 & 0.24 & 185 & 94 & 1.214 & 53 & 34.5 & 0.66 \\
Greece & 2.57 & 0 & 0.51 & 0.17 & 7 & 2 & 340 & 17.7 & 21.1 & 0.05 \\
Ireland & 5.12 & 0.61 & 1.39 & 0.46 & 65 & 43 & 542 & 32 & 33 & 2.67 \\
Sweden & 8.44 & 1.17 & 3.7 & 1.08 & 375 & 196 & 1.431 & 57 & 29.3 & 1.44 \\
EU average & 5.28 & 0.55 & 1.92 & 0.38 & 135 & 73 & 613 & 25 & 31.4 & 35.73 \\
\hline
\end{tabular}


method is known to be one of the most efficient and simplest multicriteria methodologies. It is based on the outranking relations concept which was developed by Roy $(1968,1996)$. Roy defined the outranking relation as a binary relation $\mathbf{S}$ between alternatives (countries) $a$ and $b$ in a given set of alternatives $A$, such that $a \mathbf{S} b$ ( $a$ outranks $b$ ) if there are enough arguments to decide that $a$ is at least as good as $b$, while there is no essential reason to refute that statement.

The construction of the outranking relation through the PROMETHEE II method involves the consideration of the performance of the alternatives (countries) on a set of $n$ evaluation criteria (indicators). To each criterion $j$ a weight $p_{j} \geq 0$ is given depending on its importance (the criteria weights sum up to 1 , i.e., $\sum_{j=1}^{n} p_{j}=1$ ). The higher the weight of a criterion, the more important is for the evaluation of the overall performance of the alternatives. The criteria's weights constitute the basis for the assessment of the degree of preference for alternative $a$ over alternative $b$. This degree is represented in the preference index $\pi(a, b)$ defined as follows:

$$
\pi(a, b)=\sum_{j=1}^{n} p_{j} H_{j}\left(d_{a b}\right)
$$

The preference index for each pair of alternatives $(a, b)$ ranges between 0 and 1 . The higher it is (closer to 1 ) the higher is the strength of the preference for $a$ over $b$. According to (1) the preference index is calculated as the weighted average of the partial preference of $a$ over $b$ on each criterion $j$. To measure the partial preference of $a$ over $b$ on a criterion $j$ the function $H_{j}\left(d_{a b}\right) \in[0,1]$ is used; this is an increasing function of the difference $d_{a b}=g_{a j}-g_{b j}$ between the performance of alternative $a$ on criterion $j\left(g_{a j}\right)$ and the performance of alternative $b$ on the same criterion $j\left(g_{b j}\right)$. $H_{j}\left(d_{a b}\right)$ is a kind of preference intensity function (Vincke, 1992). In the case alternatives $a$ and $b$ have similar performance on criterion $j$ and consequently the preference of $a$ over $b$ is expected to be low, i.e., $H_{j}\left(d_{a b}\right) \approx 0$. On the other hand, the case $d_{a b}=g_{a j}-g_{b j}>0$ designates that the performance of alternative $a$ on criterion $j$ is considerably higher than the performance of alternative $b$, and consequently it is expected that $a$ is strongly preferred to $b$, i.e., $H_{j}\left(d_{a b}\right) \approx 1$. The function $H_{j}$ can be of different forms, depending upon the judgment policy of the decision maker. Brans $\&$ Vincke (1985) proposed the six general forms of Table 3 which cover a wide range of practical situations.

For the purposes of this study the Gaussian form of the $H_{j}$ was used for all criteria. The use of the Gaussian form requires the specification of only one parameter $(\sigma)$. Furthermore, it should be noticed that the Gaussian function is a generalization of all the other five forms, whereas the fact that it does not have 
Economic and Technological Aspects of the European Competitiveness: A Multicriteria Approach 697

discontinuities contributes to the stability and the robustness of the obtained results (Brans et al., 1986).

Table $3^{*}$ Forms of the preference function (Source: Brans et al., 1986)

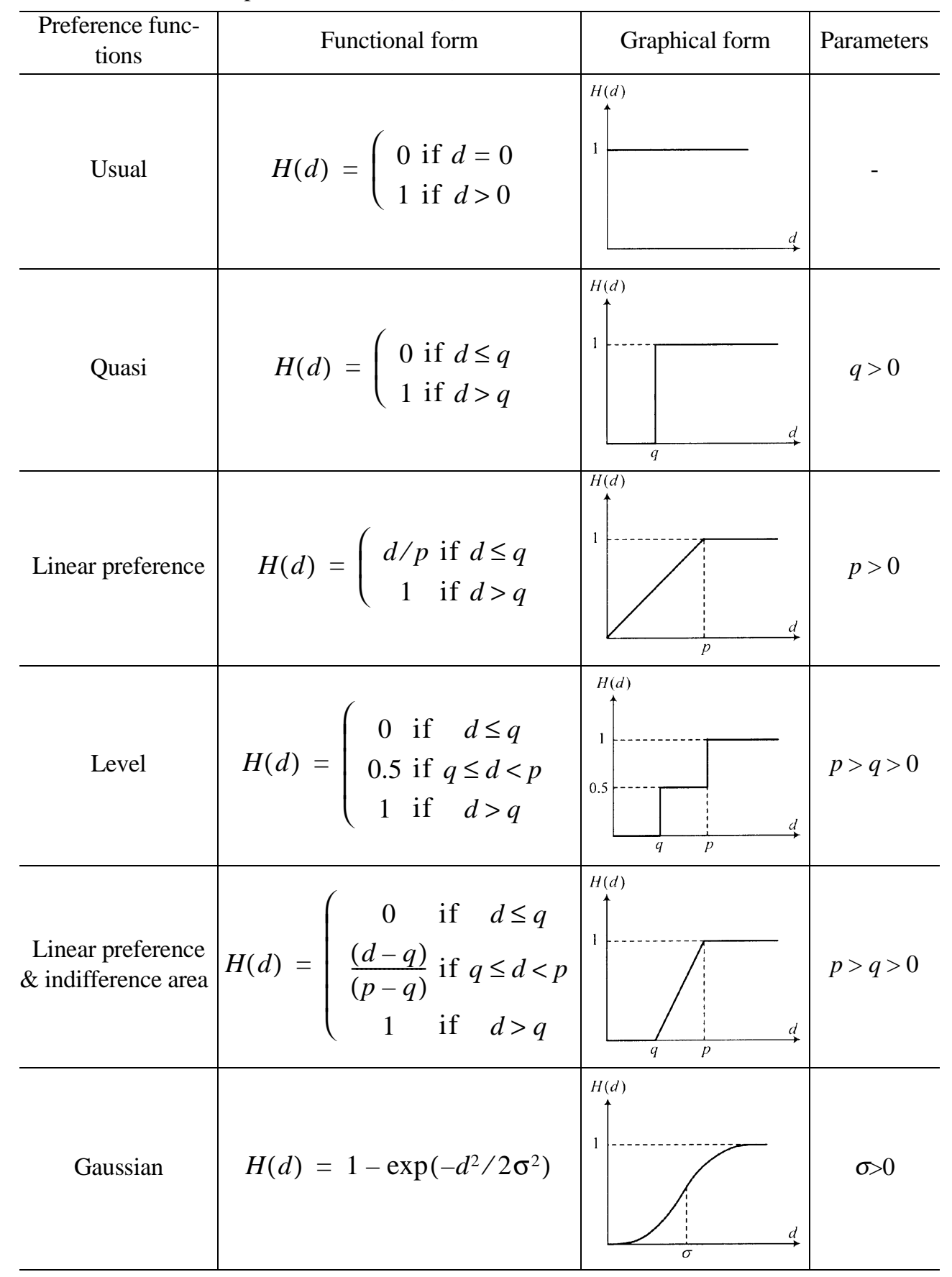


The results of the comparisons made for all pairs of alternatives $(a, b)$ are organized in a directed graph (value outranking graph), such as the ones shown in Figure 1 . The nodes of the graph represent the alternatives under consideration, whereas the arcs connecting pairs of nodes $a$ and $b$ represent the preference of alternative $a$ over alternative $b$ (if the direction of the arc is $a \rightarrow b$ ) or the opposite (if the direction of the arc is $b \rightarrow a$ ). Each arc is associated with a flow representing the preference index $\pi(a, b)$ as defined in (1). The sum of all flows leaving a node $a$ is called the leaving flow of the node, denoted by $\phi^{+}(a)$. The leaving flow provides a measure of the outranking character of alternative $a$ over all the other alternatives. In a similar way, the sum of all flows entering a node $a$ is called the entering flow of the node, denoted by $\phi^{-}(a)$. The entering flow measures the outranked character of alternative $a$ compared to all the other alternatives. The difference between the leaving and the entering flow $\phi(a)=\phi^{+}(a)-\phi^{-}(a)$ provides the net flow for the node (alternative) $a$ which constitutes the overall evaluation measure of the performance of the alternative $a$. Assuming that $m$ alternatives are considered, the net flow may range in $[-m, m]$. The case $\phi(a) \approx-m$ designates that alternative $a$ is strongly outranked by the other alternatives, whereas the case $\phi(a) \approx m$ designates that alternative $a$ strongly outranks the other alternatives. On the basis of their net flows the alternatives are ranked from the best (alternatives with high positive net flows) to the worst ones (alternatives with low net flows).

Using the methodology that is described above, the PROMETHEE II contributes significantly towards making an integrated and rational evaluation and assessment of the competitiveness of European countries, as far as their economic and technological aspects are concerned.

Figure 1. Example of a value outranking graph

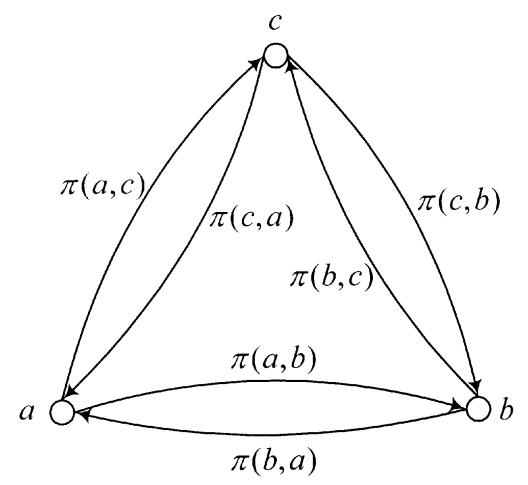

Flows:

$\phi(a)=\phi^{+}(a)-\phi^{-}(a)=[\pi(a, b)+\pi(a, c)]-[\pi(b, a)+\pi(c, a)]$

$\phi(b)=\phi^{+}(b)-\phi^{-}(b)=[\pi(b, a)+\pi(b, c)]-[\pi(a, b)+\pi(c, b)]$

$\phi(c)=\phi^{+}(c)-\phi^{-}(c)=[\pi(c, a)+\pi(c, b)]-[\pi(a, c)+\pi(b, c)]$ 


\section{Results}

Taking into consideration the 10 indicators that were derived from the European Commission's report, as mentioned above, an assessment procedure through the PROMETHEE II method was carried out. As previously mentioned, this application requires the determination of the appropriate evaluation criteria and also the shape of the $H_{j}$ function for each selected evaluation criterion $j$. The shape of the $H_{j}$ function that was selected for each criterion $j$, is the Gaussian form (Gaussian criterion) defined as $H_{j}(d)=1-\exp \left(-d^{2} / 2 \sigma_{j}^{2}\right)$. For the parameters $\sigma_{j} 10$ different scenarios were considered ranging between $0.25 s_{j}$ and $2.5 s_{j}$, where $s_{j}$ is the standard deviation of all differences $d_{a b}$ for all countries $a$ and $b$ on criterion $j$. When low values for $\sigma$ are considered the preference for a country $a$ over a country $b$ can be high even when the performance of the two countries on the criteria are similar. On the other hand, when higher values for $\sigma$ are employed the preference for a country $a$ over a country $b$ will be high only if the performance of country $a$ on the criteria set is considerably higher than the performance of country $b$.

A simulation approach was also employed for the criteria weights required to calculate the preference index in (1). In particular, 50 random weighting scenarios were generated. In each scenario the criteria weights are considered as random numbers uniformly distributed in the interval $[1,100]$.

The combination of the 50 weighting scenarios with the 10 scenarios of the parameter $\sigma$ resulted to the consideration of 500 scenarios overall. In each scenario a different ranking of the countries is obtained according to the corresponding parameters of the PROMETHEE II method. To measure the similarities of the results (ranking of the countries) obtained for each scenario the Kendall's coefficient of concordance (Kendall's $W$ ) is used. The Kendall's $W$ ranges in $[0,1]$ and measures the similarities between a set of rankings. The case $W=1$ indicates that all rankings coincide, whereas the case $W=0$ indicates a significant disagreement. In this analysis the Kendall's $W$ is employed to investigate the robustness of the evaluation results when different parameters of the PROMETHEE method are considered. The Kendall's $W$ for the results obtained in the 500 scenarios of the analysis was found 0.931 (significant at the $1 \%$ level) indicating the robustness of the evaluation results.

Table 4 presents some basic statistics (across all 500 scenarios) regarding the results of this analysis, both in terms of the net flows of the countries as well as in 
terms of their ranking. According to the obtained results, Sweden leads in competitiveness, followed by Finland, USA, Denmark, Germany, The Netherlands, Japan and Belgium. In the 500 scenarios of the analysis Sweden was always among the two best performing countries, whereas Finland was always among the best four performing countries. Finland and Sweden appear to have a high ratio of competitiveness, due to the technological development, the quality of public institutions and the macroeconomic environment. The last five positions, on the other end, are occupied by Ireland, Italy, Spain, Portugal and Greece. It should be noted that Portugal and Greece are found among the two worst performing countries in all scenarios of the analysis, whereas Ireland, Italy and Spain are also found among the worst performing countries in all scenarios. The countries in this group seem to have low ratio of competitiveness and technological development. Moreover, it is interesting to note that the countries of the Northern Europe, such as Sweden, Finland, Denmark, Germany and the Netherlands are above the EU average performance. On the other hand, the countries of the Southern Europe that is Italy, Spain, Portugal and Greece occupy the last four ranking positions in competitiveness from the economic and technological development point of views with average net flows below the EU average.

Table 4 Summary results

\begin{tabular}{l|rrrr|rrrr}
\hline \multirow{2}{*}{ Countries } & \multicolumn{5}{c|}{ Net flows } & \multicolumn{4}{c}{ Rankings } \\
\cline { 2 - 8 } & Average & Median & Max & \multicolumn{1}{c|}{ Min } & Average & Median & Max & Min \\
\hline Sweden & 6.03 & 5.34 & 13.11 & 1.59 & 1.00 & 1 & 1 & 2 \\
Finland & 4.64 & 3.95 & 12.42 & 0.93 & 2.15 & 2 & 2 & 4 \\
USA & 2.68 & 2.19 & 9.54 & -0.29 & 3.36 & 3 & 1 & 11 \\
Denmark & 1.60 & 1.10 & 6.66 & -0.02 & 5.04 & 5 & 3 & 10 \\
Germany & 1.42 & 0.78 & 6.65 & 0.00 & 5.80 & 6 & 3 & 9 \\
The Netherlands & 1.17 & 0.68 & 5.88 & -0.04 & 6.31 & 6 & 3 & 10 \\
Belgium & 0.84 & 0.49 & 5.46 & -0.21 & 7.60 & 8 & 3 & 11 \\
Japan & 0.70 & 0.49 & 7.65 & -3.87 & 7.68 & 8 & 4 & 11 \\
EU average & 0.54 & 0.38 & 2.92 & -1.08 & 7.77 & 8 & 4 & 13 \\
France & 0.48 & 0.12 & 4.24 & -0.55 & 8.99 & 9 & 5 & 11 \\
Gr. Britain & -0.20 & -0.24 & 2.58 & -1.76 & 10.53 & 11 & 6 & 13 \\
Austria & -0.98 & -0.80 & 0.06 & -3.62 & 12.32 & 12 & 10 & 13 \\
Ireland & -1.07 & -0.84 & 0.10 & -4.18 & 12.45 & 13 & 10 & 13 \\
Italy & -3.33 & -2.50 & -0.60 & -10.13 & 14.25 & 14 & 14 & 15 \\
Spain & -3.79 & -2.82 & -0.97 & -10.15 & 14.75 & 15 & 14 & 15 \\
Portugal & -5.23 & -4.24 & -1.33 & -13.04 & 16.11 & 16 & 16 & 17 \\
Greece & -5.50 & -4.41 & -1.49 & -13.62 & 16.89 & 17 & 16 & 17 \\
\hline
\end{tabular}


A comparison of the obtained results to the ranking of the countries in 2003 according to the World Competitiveness Yearbook (WCY; cf. Institute of Management Development, 2003), is presented in Table 5. WCY is published annually by the Institute of Management Development providing an overall analysis of the competitiveness of the countries based on several competitiveness indicators. Two rankings are specified in the WCY competitiveness analysis: one for countries with population higher than 20 million and one for countries with population lower than 20 million. Therefore, the comparison of the obtained results to the WCY analysis is based on this grouping of the countries. For the group of small countries the results of the present analysis have some significant similarities with the WCY ranking. In particular, in both cases Portugal and Greece are found to be the countries with the lowest level of competitiveness, whereas the Scandinavian countries (Sweden, Finland and Demark) are found to have the highest level of competitiveness. With regard to the group of larger countries, both the present analysis as well as the WCY results coincide with respect to the most competitive countries (in both cases USA and Germany are found to have the highest competitiveness). On the other hand, with regard to the least competitive countries there are some apparent differences, mainly with regard to Japan and Spain. These differences, are mainly due to the different time context of the analysis (the WCY report involves 2003, whereas the present analysis is based on past data) and also to the kind of data employed (WCY considers a rich set of indicators, whereas the present study considers a compact set of 10 competitiveness indicators). Nevertheless, it should be noted that the results of this

Table 5. Comparison of the obtained results to the World Competitiveness Yearbook (WCY) rankings

\begin{tabular}{lcc|lcc}
\hline \multicolumn{2}{c|}{ Countries with population $<20$ million } & \multicolumn{2}{c}{ Countries with population $>20$ million } \\
\hline Sweden & $\begin{array}{c}\text { Obtained } \\
\text { ranking }\end{array}$ & $\begin{array}{c}\text { WCY } \\
\text { ranking }\end{array}$ & & $\begin{array}{c}\text { Obtained } \\
\text { ranking }\end{array}$ & $\begin{array}{c}\text { WCY } \\
\text { ranking }\end{array}$ \\
Finland & 1 & 3 & USA & 1 & 1 \\
Denmark & 2 & 1 & Germany & 2 & 2 \\
The Netherlands & 3 & 2 & Japan & 3 & 6 \\
Belgium & 4 & 4 & France & 4 & 4 \\
Austria & 5 & 7 & Gr. Britain & 5 & 3 \\
Ireland & 6 & 5 & Italy & 6 & 7 \\
Portugal & 7 & 6 & Spain & 7 & 5 \\
Greece & 8 & 8 & & & \\
\hline
\end{tabular}


study are, generally, quite similar to the ranking of the countries in WCY.

\section{Conclusions}

This paper examined the economic and technological aspects of the competitiveness of European countries, including USA and Japan for comparison reasons with the aid of the multicriteria ranking methodology PROMETHEE.

Concluding we observe that although, its introduction to the euro zone and the amelioration of its macroeconomic sizes, Greece should develop the relevant technological infrastructure to succeed high competitiveness and to ensure development as well as socioeconomic wealth in the long run. Similar conclusions can also be drawn for the other countries of southern Europe, which are also found to have poor performance in terms of their competitiveness. The investments towards the amelioration of the educational system, the foundation of new firms, the promotion of technological innovations, as well as the development of an "information society" will contribute to the improvement of the competitiveness and the attainment of economic and social purposes.

Finally, a larger amount of countries and indicators could be taken into consideration, in order to indicate more realistically the competitiveness of countries. Moreover, comparisons with other MCDA methods and statistical multivariate techniques should also take place in order to prove the comparative ability of the methods concerning the ranking of countries from the competitiveness point of view.

Received 23 May 2002, Accepted 3 June 2003

\section{References}

Brans, J.P. and Vincke, Ph. (1985), “A preference ranking organization method: The PROMETHEE method for multiple criteria decision-making," Management Science, 31(6): 647-656.

Brans, J.P., Vincke, Ph. and Mareschal, B. (1986), "How to rank and how to select projects: The PROMETHEE method," European Journal of Operational Research, 24: 228-238.

European Commission (2001), Towards a European Research Area Key Figures 2001 Special Edition: Indicators for Benchmarking of National Research Policies, European Commission, Research Directorate General, Brussels. 
Institute of Management Development (2003), World Competitiveness Yearbook, (http:// www01.imd.ch/wcy/ranking/).

Oral M. and Chabchoub H. (1996), "On the methodology of the World Competitiveness Report," European Journal of Operational Research, 90: 514-535.

Oral M. and Chabchoub H. (1997), "An estimation model for replicating the ranking of the world competitiveness report," International Journal of Forecasting, 13: 527537.

Porter, M. E. (1990), The Competitive Advantage of Nations, Free Press, New York.

Roy, B. (1968), "Classement et choix en présence de points de vue multiples: La méthode ELECTRE,” R.I.R.O, 8: 57-75.

Roy, B. (1996), Multicriteria Methodology for Decision Aiding, Kluwer Academic Publishers, Dodrecht.

Vincke P. (1992), Multicriteria Decision Aid, John Wiley \& Sons Ltd, New York.

Zopounidis, C. (1998), Operational Tools in the Management of Financial Risks, Kluwer Academic Publishers, Dordrecht.

Zopounidis, C. (2001), "Evaluation of the competitiveness of countries based on their macroeconomic variables," European and International Management Magazine, 40 (330): 96-98 (in Greek).

Zopounidis, C. (2001), Multicriteria Analysis of Financial Decisions, Anikoula Editions, Thessaloniki (in Greek). 